\title{
BODY MASS INDEX IN THALASSEMIA CHILDREN
}

\author{
Pranoy Dey¹, Gitashree Konwar², Bikash Sarkar ${ }^{3}$
}

${ }_{1}^{1}$ Associate Professor, Department of Paediatrics, Assam Medical College and Hospital, Dibrugarh, Assam, India. 2Postgraduate Trainee, Department of Paediatrics, Assam Medical College and Hospital, Dibrugarh, Assam, India. 3Postgraduate Trainee, Department of Paediatrics, Assam Medical College and Hospital, Dibrugarh, Assam, India.

\section{ABSTRACT}

\section{BACKGROUND}

Thalassemia is more common in populations in the geographic belt from south east Asia to Africa and it is more common in an around Dibrugarh District of Assam, India. Most of the time, children present with either anaemia or failure to thrive especially seen in children belonging to tea garden area. Along with other laboratory parameters, anthropometric measurements are important especially BMI to see the status of the growth pattern. Quetlet index also known as BMI has been in use to study the growth parameters since a long time and is still being used. We wanted to study the Body Mass Index (BMI) in children with thalassemia major to determine the status of malnutrition in thalassemia, who were on regular blood transfusion therapy.

\section{METHODS}

50 beta thalassemia major patients, 5-15 years of age, were examined for body mass index in a tertiary care centre. They were on regular blood transfusion. This is a hospital based observational study in the Department of Paediatrics, Assam Medical College, Dibrugarh, Assam, India.

\section{RESULTS}

BMI was found to be reduced in patients of thalassemia major who were more than 10 years of age (70.4\% of patients) as compared to patients of less than 10 years of age (30.4\% of patients). However, the variation of BMI between girls and boys was not significant, but the differences begin to appear when thalassemia is running for a longer period of time. Whether regular blood transfusion therapy/other medical problems/nutritional problems lead to the differences needs to be studied. BMI was normal in most of the cases of below 10 years age group either because of not attaining adolescent period yet, or may be because of regular blood transfusions for a short period of time, as compared to children of more than 10 years of age.

\section{CONCLUSIONS}

Thalassemia major has a significant impact on growth process of children and hence early intervention is needed and further studies may help us determine as to whether BMI impact is because of disease itself or due to something else.

HOW TO CITE THIS ARTICLE: Dey P, Konwar G, Sarkar B. Body mass index in thalassemia children. J. Evolution Med. Dent. Sci. 2019;8(19):1537-1539, DOI: 10.14260/jemds/2019/341

\section{BACKGROUND}

The word Thalassemia is a Greek term derived from 'Thalassa' which means the 'sea' and 'emia' means related to 'blood'. Thalassemia should be considered in the differential diagnosis of any child with hypochromic, microcytic anaemia that does not respond to iron supplementation. Children with $\beta$ thalassemia major usually demonstrate no symptoms until about 3-6 months of age, when $ß$ chains are needed to pair with $\alpha$ chains to form $\mathrm{Hb} \mathrm{A}$, since $\mathrm{Y}$ chains production is turned off. However, in some cases, the condition may not be recognized till 3-5 yrs., of age due to a delay in cessation of $\mathrm{Hb} \mathrm{F}$ production. Severe pallor and hepatosplenomegaly are almost always present. Icterus is usually absent, but mild to moderate jaundice may occur due to liver dysfunction from iron overload and chronic hepatitis.

'Financial or Other Competing Interest': None.

Submission 19-02-2019, Peer Review 23-04-2019,

Acceptance 30-04-2019, Published 13-05-2019.

Corresponding Author:

Dr. Pranoy Dey,

Associate Professor, Department of Paediatrics,

Assam Medical College and Hospital,

P.O. Borbari District, Dibrugarh-786002, Assam, India.

E-mail: pranoydey241@gmail.com

DOI: $10.14260 /$ jemds $/ 2019 / 341$

(c) (i) $($ )
Symptoms of severe anaemia such as intolerance to exercise, irritability, heart murmur or even signs of frank heart failure may be present. Bony abnormalities, such as frontal bossing, prominent facial bones and dental malocclusion are usually present. Ineffective erythropoiesis leads to a hypermetabolic state associated with fever and failure to thrive; hence body mass index can be used as a tool to recognise early nutritional status of thalassaemic children.

Hyperuricemia may be encountered. Beta thalassemia is a severe haemolytic anaemia and it is the most common single gene abnormality.(1) In recent years, patients with thalassemia major have shown a better life expectancy because of intensive transfusion and chelation agents. However various complications are seen in these patients due to progressive iron deposition in vital organs like heart, liver and endocrine organs. There is also increased absorption of iron in the gut due to ineffective erythropoiesis.(2) Beta thalassemia major is associated with impaired growth velocity, generally beginning after 6 to 8 years, which results in stunting.(3,4) Around 30\% to 50\% of children with beta thalassemia major develops growth failure.(5) The key factor responsible for growth disturbances include chronic anaemia with ineffective erythropoiesis, under nutrition, iron overload resulting in chronic lung and cardiac dysfunction, endocrine dysfunction. 


\begin{tabular}{|c|c|c|c|c|}
\hline Age Group (In Years) & Male & Female & Total & (\%) \\
\hline $5-9$ & 14 & 9 & 23 & 46.00 \\
\hline $10-15$ & 12 & 15 & 27 & 54.00 \\
\hline Total Table 1. Sex and Age Distribution & $\mathbf{2 4}$ & $\mathbf{5 0}$ & $\mathbf{1 0 0 . 0 0}$ \\
\hline \multicolumn{2}{|r}{} \\
\hline
\end{tabular}

\begin{tabular}{|c|c|c|c|c|c|c|}
\hline \multirow{2}{*}{ Variables } & \multicolumn{3}{|c|}{ 5-9 Years } & 10-15 Years \\
\cline { 2 - 7 } & Mean & S.D. & Coefficient of Variance & Mean & S.D. & Coefficient of Variance \\
\hline Weight $(\mathrm{Kg})$ & 18.22 & 3.09 & 16.96 & 25.15 & 5.69 & 22.62 \\
\hline Height $(\mathrm{cm})$ & 116.83 & 8.29 & 7.10 & 133.59 & 9.62 & 7.20 \\
\hline BMI $(\mathrm{Kg} / \mathrm{m} 2)$ & 13.33 & 1.64 & 12.29 & 13.96 & 1.48 & 10.57 \\
\hline \multicolumn{7}{|c|}{ Table 2. Mean, Standard Deviation and Coefficient of Variance } \\
\hline
\end{tabular}

\begin{tabular}{|c|c|c|c|c|}
\hline \multirow{3}{*}{$\begin{array}{l}\text { Age Group } \\
\text { (in Years) }\end{array}$} & \multicolumn{4}{|c|}{ BMI Percentile } \\
\hline & \multicolumn{2}{|c|}{ Boys } & \multicolumn{2}{|c|}{ Girls } \\
\hline & $<\mathbf{1 0 \%}$ & $>90 \%$ & $<\mathbf{1 0 \%}$ & $>90 \%$ \\
\hline $5-9$ & 4 & 0 & 3 & 0 \\
\hline $10-15$ & 7 & 0 & 12 & 0 \\
\hline Total & 11 & $\mathbf{0}$ & 15 & $\mathbf{0}$ \\
\hline \multicolumn{5}{|c|}{ Table 3. BMI Percentiles in Children with Beta Thalassemia Major } \\
\hline
\end{tabular}

Side effects of chelation therapy on skeletal growth and psychosocial stress. BMI is a measurement of a person leanness or corpulence based on their height and weight and is intended to quantify tissue mass.

BMI is an important anthropometric measurement to find out fat content,(6) and it is measured by the formula-

BMI= Weight $(\mathrm{kg}) /$ Height $\left(\right.$ meter $\left.^{2}\right)$

Obesity and underweight are measured in a variety of ways the selection of which relies on accuracy and feasibility. BMI is one of the easy and simple technique to find out underweight in adults which is defined as BMI < 18.5 and obesity is BMI > 30.(7) Both obesity and underweight has an impact on different activities of life and finally leads to poor outcome.(8) Some study showing very important relationship like inverse association between BMI and Work-disabling morbidity.(9)

Very few studies have been conducted to see the status of BMI in thalassemia patient hence the study undertaken with an idea whether regular blood transfusion are maintaining balance in nutritional status or not.

\section{METHODS}

50 beta thalassemia major patients of 5 to 15 years of age who are registered in Assam Medical College and Hospital, Dibrugarh, who were on regular blood transfusion therapy were included in this hospital based observational study after obtaining approval from institutional ethics committee. Study conducted from $01 / 02 / 2018$ to $30 / 11 / 2018$. Written consent was taken from all the patients included in the study. Medical history was taken. Physical and anthropometric examination was done and required data including age, sex, height, weight were taken. In the study, BMI (Weight/height 2) was calculated for both boys and girls at different ages and was compared with standardized percentile curves of BMI for children and adolescents.(10) In the study, less than 10th percentile of BMI was considered as underweight. All the data were analysed using SPSS.

\section{RESULTS}

The study was conducted with a total number of 50 thalassemia major patients ( $52.0 \%$ male and $48.0 \%$ female).
The mean age of the patients was $9.48 \pm 2.60$. Table 1 shows the distribution of the patients according to their age and sex. Table 2 shows the BMI calculated at different ages for both sexes. $33.3 \%$ of girls and $28.6 \%$ of boys (Totally in $30.4 \%$ of patients), of under 10 years of age showed a BMI of less than 10th percentile. However, it was significantly higher in patients of above 10 years of age. $80 \%$ of girls and $58.3 \%$ of boys (Totally in $70.4 \%$ of patients) had BMI of less than 10 th percentile in this age group.

It is important to note that the observed difference in BMI values in patients under 10 years of age and more than 10 years of age is statistically significant $(\mathrm{p}<0.000001)$. However, the observed difference between girls and boys, especially when they are more than 10 years of age is not significant.

From the data presented in Table 2, it is obvious that overweight (defined as BMI > 90th percentile for sex and age) is not seen in patients with thalassemia major.

\section{DISCUSSION}

To assess malnutrition, BMI is one of the most suitable and preferred methods. Both underweight and obesity are major causes of mortality and morbidity in our country and it is always important to find out these derangements as early as possible to prevent the adverse consequences. We have seen that obesity was not a problem in patients with thalassemia major in this study. On the other hand, underweight (Low BMI) was a common finding in these patients specially when they were older than 10 years of age. BMI low in thalassemia patients has also been a outcome in many other studies also. In a study conducted by Aliakbar et al. $12.4 \%$ of thalassaemic patients under 10 years of age showed a BMI of less than 10th percentile compared to $46.5 \%$ of patients above 10 years of age $(\mathrm{p}<$ 0.000001).

The cause of under nutrition in thalassemia major patients is multifactorial. Endocrinopathies including hypothyroidism, hypogonadotropic gonadism, growth hormone deficiency, hypoparathyroidism are the major causes of under nutrition in these patients. $(3,11,12)$ Because underweight leads patients to greater mortality and 
morbidity risks, it is important to pay more attention to take this problem in thalassaemic patients into consideration. Monitoring for endocrine dysfunction starts early, around 5 yrs., of age, or after at least 3 yrs., of chronic transfusions. All children require monitoring of their height, weight, and sitting height semi-annually,(13) in order to detect any decline in growth velocity and also any derangement in BMI to establish an appropriate protocol for investigation and management.

\section{CONCLUSIONS}

Thalassemia imposes major disruption in the family and creates significant obstacles to normal development. A team approach consisting of a paediatrician, nutritionist and an endocrinologist is required in management of a child with thalassemia major. Thorough evaluation should be started early, preferably before 5 years of age. Thus, endocrinopathy and nutritional deficiency should be prevented through a regular transfusion schedule, chelation agents, maintaining an optimal nutritional status and prompt recognition and treatment of co-morbidities.

\section{REFERENCES}

[1] Weatherall DJ. The Thalassemias: disorders of globinsynthesis. Chap - 48. In: Kaushansky K, edr. William's Haematology. 9th edn. New York: McGrawHill Publication 2016: p. 725.

[2] Singh P, Seth A. Growth and endocrine issues in children with thalassemia. Pediatric Hematology Oncology Journal 2017;2(4):98-106. doi: 10.1016/j.phoj.2017.12.005

[3] Kattamis C, Liakopoulou T, Kattamis A. Growth and development in children with thalassemia major. Acta Paediatr 1990;79(366):111-7.
[4] Constantoulakis M, Panagopoulos G, Augoustaki O. Stature and longitudinal growth in thalassemia major. A study of 229 Greek patients. Clin Pediatr (Phila) 1975;14(4):355-7/362-8.

[5] Toumba M, Sergis A, Kanaris C, et al. Endocrine Complications in patients with thalassemia major. Pediatr Endocrine Rev 2007;5(2):642-8.

[6] Elizabeth KE. Nutrition \& Child Development. Triple burden of malnutrition. Section 4. $5^{\text {th }}$ edn. New Delhi: Paras Medical Publisher 2014: p. 263.

[7] Mahan LK, Escott-Stump S. Krause's Food, nutrition, and diet therapy. $10^{\text {th }}$ edn. Philadelphia: WB Saunders Company 2000;370:493-4, 511-3.

[8] Bray GA, Groy DS. Obesity. Part II--treatment. West J Med 1988;149(5):555-71.

[9] Pryer JA. Body mass index and work-disabling morbidity: results from a Bangladeshi case study. Eur J Clin Nutr 1993;47(9):653-7.

[10] Hammer LD, Kraemer HC, Wilson DM, et al. Standardized percentile curves of body mass index for children and adolescents. Am J Dis Child 1991;145(3):259-63.

[11] Tienboon P. Sanguansermsri T, Fuchs GJ. Malnutrition and growth abnormalities in children with beta thalassemia major. Southeast Asian J Trop Med Pub Health 1996;27(2):356-61.

[12] Filosa A, Di-Maio S, Esposito G, et al. Persistence of delayed adrenarche in boys with thalassaemia. J Ped Endocrinol Metabol 2001;14(4):407-14.

[13] Michael R, De Baun, Melissa J, et al. Thalassemia Syndromes. Ch - 462.10 In: Kliegman RM, Bonita F. Stanton BF, St. Geme III JW, et al. eds. Nelson textbook of Pediatrics. 20th edn. Philadelphia: Elsevier 2016: p. 2352. 